\title{
O UNIVERSO SIMBÓLICO NA FICÇÃO DE MARIA DE LOURDES HORTAS
}

\section{Zuleide Duarte}

A configuração romanesca da personagem melancólica em Maria de Lourdes Hortas, bem como a manifestação do desejo da impossível ubiquiidade a que se associam sentimento de culpa, sexualidade reprimida, estranhamento e identidade fragmentada, estruturam-se na obra através de símbolos fortes, como a água, mar, rios e fontes, a terra e a casa, representando imagens idealizadas do paraíso perdido, além dos elementos bíblicos anteriormente estudados.

A palavra símbolo, pelo étimo, indica elemento cortado em dois ou mais pedaços cuja reunião constitui um sinal de reconhecimento. A idéia remete sempre a uma estrutura de substituição: um elemento ocupa o lugar de outro, criando-se um mecanismo de intermediação entre o sujeito e o objeto simbolizado.

A Psicanálise atribui grande relevância à relação simbólica, encarando-a, no sentido lato, como um elo entre o pensamento latente inconsciente e o conteúdo manifesto consciente. Buscaremos a compreensão de determinados elementos da trama simbolizados no discurso ficcional a partir de uma relação contextualizada, tentando sempre articular a atividade hermenêutica com a teoria freudiana. A propósito do símbolo, é esclarecedor o seguinte comentário de Freud ${ }^{1}$ :

Em diversos casos, o elemento comum entre um símbolo e o que ele representa é óbvio; em outros, acha-se oculto, e a escolha do símbolo parece enigmática. São precisamente estes últimos casos que devem ser capazes de lançar luz sobre o sentido último da relação simbólica, e eles indicam que esta é de natureza genética. As coisas que estão hoje simbolicamente ligadas provavelmente estiveram unidas em épocas préhistóricas pela identidade conceitual e lingüistica. A relação simbólica parece ser uma relíquia e um marco de identidade anterior.

1 FREUD, Sigmund. Representação por símbolos nos sonhos. Vol. V, p. 375 . 
A linguagem literária é, por natureza, simbólica, o que a torna material precioso para uma leitura psicanalítica. Isto ocorre particularmente nos textos de caráter intimista, como os do gênero lírico ou os diários, que favorecem esse tipo de leitura. É importante frisar que as imagens não trazem um significado fixo, variando conforme as situações da narrativa.

$\mathrm{Na}$ análise a que procederemos neste texto, buscamos enfatizar o caráter imagístico-simbólico da ficção de Maria de Lourdes Hortas, cujo cerne referencial é o próprio sujeito buscando formas de expressão. Salienta-se que o universo hortiano utiliza um mesmo símbolo com possibilidades interpretativas muitas vezes díspares, como é o caso do uso do olhar na narrativa. Numa primeira leitura, poder-se-ia interpretar o símbolo do olho enquanto representação de um superego vigilante, caso do texto de Adeus Aldeia, quando é feita a descrição da telefonia ou rádio que, noticiando a guerra, remete para a idéia de medo e repressão:

[...] abrigando o mistério de sons aquáticos, a caixa, com seu olho aceso (vigilante) e rede acetinada, amedrontava-a pelo tempo do jantar que durava anos ( $A A$, p. 138).

olhar ${ }^{2}$ Ainda na mesma obra registramos a presença da imagem do de cumplicidade afetiva:

Os dois olharam-se, e depois Catarina olhou para o chão, escondendo as contas azuis que haviam fascinado Adelino desde a primeira vez ( $A A$, p. 55).

Em Diário das chuvas a duplicidade da imagem é mais recorrente; o olho vigilante é retomado em vários momentos da narrativa como, por exemplo, num episódio em que Tâmara vai a uma festa sozinha e fica exposta aos olhares curiosos e censuradores dos homens presentes. Ou, mais fortemente, em um sonho-pesadelo com animais que a fixavam, assustando-a com um olhar que a paralisava:

2 "O olhar é carregado de todas as paixões da alma e dotado de um poder mágico, que the confere uma terrível eficácia. O olhar é o instrumento das ordens interiores: ele mata, fascina, fulmina, seduz, assim como exprime." Cf. CHEVALIER, Jean e GHEERBRANT, Alain. Dicionário de símbolos. 1989, p.653. 


\section{Então vieram os bichos $[\ldots]$}

A seguir foi o sapo. Debaixo da dobra da colcha ele a fixava, mexia-se, saía gordo, volumoso [...]

Os magos, talvez eles, mirassem os mortais do modo com Gabriel olhava as pessoas: primeiro violentando-as, depois ausentândo-se no insondável (p. 24).

Num terceiro momento aparecem os gatos. Também um trio, como o outro. Sem voz, passos veludosos e olhar elétrico.

[...] Por último veio a cobra. Esquisita, sem vida, como se de pano, boca cerzida, olhos de retrós (p. 44).

Em outros momentos da mesma obra registram-se as imagens dos olhos, relacionadas ao aparecimento benfazejo de Gabriel na vida da personagem Tâmara, como que em um anúncio de renascimento e natividade.

Em seus olhos, os reflexos das auroras que viu nascer incidindo sobre mim, me encandeavam [...] (p. 11).

Com esse olhar, Gabriel umedecia o meu (p. 11).

lluminando as trevas

com o luar dos seus olhos? (p. 23).

Outro elemento que se pode ler enquanto representação simbólica é o emprego reiterado de determinados números nos textos de Maria de Lourdes Hortas. O número sete ${ }^{3}$, por exemplo, é cabalístico e aparece com muita freqüência: são sete os dias da viagem de Portugal para o Brasil, sete dias de mar e, numa referência até bastante explícita ao episódio bíblico de José do Egito quando se fala a respeito na volta da família Gama à aldeia: a chegada dos presentes "e os cestos, que chegavam para bíblicos sete anos de fome, faziam par com os garrafões, para bíblicos sete anos de sede" (AA, p. 156). O

3 "O sete corresponde aos sete dias da semana, aos sete planetas, aos sete graus da perfeição, às sete cabeças da naja Angkor, aos sete galhos da árvore cósmica e sacrificial do xamanismo etc." Cf. CHEVALIER, Jean e GHEERBRANT, Alain. Op. cit., p.826. 
sete simboliza a mudança após um ciclo e uma renovação. Entre os gregos, estava ligado ao culto de Apolo, celebrado no sétimo dia do mês. Simboliza também o processo da criação: seis de dias de trabalho e o sétimo para descanso. É considerado, ainda, um número mágico, possuindo em si a perfeição. Na numerologia simbólica, o sete tem o três das pessoas da Trindade somado a quatro que representa os elementos da natureza. Sobre esse número é significativa a passagem:

Por mais que se esforçasse durante aqueles sete dias de travessia marítima, sempre que procurava imaginar o semblante da mãe, a alegria do encontro, a festa da chegada, a cena se diluía confusa, e uma inexplicável saudade the apertava o coração $(A A$, p. 131).

O número dez é outro que se repete em Adeus aldeia. Esse número tem o sentido de conclusão ou de volta à unidade. Os pitagóricos consideravam-no o símbolo da criação universal. ${ }^{4}$ Liga-se à vida e à morte. Entre os Maias, o décimo dia era considerado nefasto pois pertencia a Thoh, deus da morte. Por outro lado, o número é também emblema de fecundidade e atribuído a Faro ou Dier, deus da água. Na mitologia judaico-cristã foram dez os mandamentos ditados por Deus a Moisés no Monte Sinai. Significativamente, os Gama cumpriram um período de dez anos de exílio antes de retornarem à aldeia, como se tivessem saído da vida para a morte e, cumprido o novo ciclo, ressuscitassem.

O número quarenta, idade declarada por Tâmara, personagem de Diário das chuvas, ao iniciar o texto, tem uma significação peculiar. Em Adeus aldeia estão referidos também os quarenta anos mal vividos por Mariana:

Da idade de Mariana quarenta anos haviam-se derretido como neve ao sol ( $A A$, p. 167).

Era o décimo nono dia do nono mês do ano quarenta da minha vida. Naquele preciso instante, estava chegando à última encruzilhada do meu destino. $E$ desde essa hora segui Gabriel para sempre (DC, p. 12).

Esse número também significa expectativa, preparação e prova. Em várias tradições, o quarenta simboliza o ciclo completo da vida. Na Bíblia, caracteriza intervenções sucessivas e diretas de Deus.

4 Op. cit., p.334. 
Também está ligado à idéia de purificação e, por isso, Tâmara preparou-se durante quarenta anos para Gabriel, mantendo intocado o seu coração.

O número três é o número perfeito entre os chineses e para os cristãos está ligado à Trindade. Em muitas culturas o três tem uma simbologia especial. Entre os gregos, os senhores do universo eram Zeus, Poseidon e Hades. Freud atribui um significado sexual ao número três ${ }^{5}$. Talvez, por esta ligação com a sexualidade, no sonhopesadelo de Tâmara animais em número de três invadiram o seu quarto. Sobre esse sonho, falaremos mais detidamente a seguir.

O número cinco é usado reiteradas vezes nesta passagem:

Há cinco dias estou aqui: cinco séculos. Cinco milênios de dilúvio. Sangrando, as horas gotejam, uma a uma, no poço das ausências.

Há cinco dias estou aqui. Cinco séculos de minutos inúteis que empilho, pedra sobre pedra, muralhas da cidadela onde me fecho. (DC, p. 91)

Este número, entre outras coisas, simboliza o homem de braços estendidos, em forma de cruz. O cinco está relacionado aos sentidos, aos sabores, às vísceras, aos dedos da mão, às chagas de Cristo.

Para os pitagóricos, o cinco é considerado símbolo do casamento e da síntese. É também um número importante para os alquimistas, que procuravam a quintessência ou o quinto elemento ${ }^{6}$.

5 FREUD, Sigmund. Obras completas, XV, p.185: "Primeiramente, para os genitais masculinos, como um todo, o sagrado número três tem significação simbólica".

6 CHEVALIER, Jean e GHEERBRANT, Alain. Op. cit., p. 241-245. 


\section{REFERÊNCIAS BIBLIOGRÁFICAS}

BELLEMIN-NÖEL, Jean. Psicanálise e literatura. São Paulo: Editora Cultrix, 1983.

BRUNEL, Pierre. Dicionário de mitos literários. Trad. Carlos Sussekind [et al]. Prefácio à edição brasileira: Nicolau Sevcenko. Rio de Janeiro: José Olympio Editora, 1997.

CHEVALIER, Jean e GHEERBRANT, Alain. Dicionário de símbolos. Trad. Vera da Costa e Silva, Raul Sá Barbosa, Ângela Melim e Lúcia Melim. 2 ed. Rio de Janeiro: José Olímpio, 1989.

DUARTE, D. Leal conselheiro. Atualização ortográfica, introdução e notas de João Morais Barbosa. Lisboa: Imprensa Nacional/ Casa da Moeda, s/d.

DURAND, Gilbert. A imaginação simbólica. Trad. Eliane Fittipaldi Pereira. São Paulo: Cultrix/EDUSP, 1988.

DURAND, Gilbert. As estruturas antropológicas do imaginário: introdução à arqueologia geral. Trad. Hélder Godinho. São Paulo: Martins Fontes, 1997.

FREUD, Sigmund. Obras Completas. Rio de Janeiro: Edição Standard Brasileira, Imago, 1980.

HORTAS, Maria de Lourdes. Adeus aldeia. Trofa: Solivros de Portugal, 1990.

HORTAS, Maria de Lourdes. Diário das chuvas. Recife: Edições Bagaço, 1995.

KRISTEVA, Julia. Estrangeiros para nós mesmos. Trad. Maria Carlota Carvalho Gomes. Rio de Janeiro: Rocco, 1994.

KRISTEVA, Julia. Sol negro, depressão e melancolia. 2 ed. Trad. Maria Carlota Carvalho Gomes. Rio de Janeiro: Rocco, 1988.

LAPLANCHE, Jean. A angústia, Problemáticas I. Trad. Álvaro Cabral. São Paulo: Martins Fontes, 1987.

LEXIKON, Herder. Dicionário de símbolos. Trad. Erlom José Paschoal. São Paulo: Cultrix, 1997. 